\title{
EFFORT TO IMPROVE CONCEPTUAL UNDERSTANDING OF NATURAL RESOURCE-RELATED ECONOMIC ACTIVITIES THROUGH THE APPLICATION OF CIRCUIT LEARNING MODEL
}

\section{Riski Fitriana Sativa, Soegiyanto, Sadiman}

Universitas Sebelas Maret

riskisativa@gmail.com

\section{Article History}

accepted 09/07/2018

approved 01/08/2018

published 17/09/2018

\section{Keywords}

circuit learnng model, conceptual understanding, natural resourcerelated economic activities

\begin{abstract}
The objective of this research is to investigate the improvement of conceptual understanding of natural resourcerelated economic activities through the application of Circuit Learning model. This research used classroom action research with two cycles. Its data were collected through in-depth interview, observation, test, and documentation. They were validated by using content validity and data collection technique triangulation. The data were analyzed by using the Miles \& Huberman's interactive model of analysis. The result of the research shows that prior to the treatment 5 out of 31 students (16.13\%) fulfilled the minimal learning completeness criterion of 70 . Following the treatments, the number of the students who fulfilled the criterion was 13 students (42\%) in Cycle I and 26 (83.87\%) in Cycle II respectively. Thus, the Circuit Learning model can improve the conceptual understanding of natural resource-related economic activities of the students in Grade IV of State Primary School Karangasem IV No. 204 of Surakarta in Academic Year 2017/2018
\end{abstract}

Social, Humanities, and Education Studies (SHEs): Conference Series https://jurnal.uns.ac.id/shes
p-ISSN 2620-9284

e-ISSN 2620-9292 


\section{PENDAHULUAN}

Pemahaman konsep merupakan pembelajaran lanjutan dari penanaman konsep yang bertujuan agar siswa lebih memahami suatu konsep (Heruman, 2012: 3). Pemahaman terhadap konsep-konsep dibedakan dalam tujuh dimensi yaitu atribut, struktur, keabstrakan, keinklusifan, generalitas, ketepatan, dan kekuatan. Sehingga pemahaman konsep merupakan memahami suatu konsep yang memiliki atribut, struktur, keabstrakan, keinklusifan, generalisasi, ketepatan, dan kekuatan tertentu.

IImu pengetahuan sosial atau yang disingkat dengan IPS merupakan salah satu mata pelajaran yang diberikan mulai dari sekolah dasar sampai sekolah menengah dengan menyajikan materi yang mengkaji seperangkat peristiwa, fakta, konsep, dan generalisasi yang berkaitan dengan isu-isu sosial (Susanto, 2016: 159). Siswa sekolah dasar yang diberi mata pelajaran IPS diharapkan dapat memiliki ilmu pengetahuan dan wawasan tentang konsep dasar ilmu sosial dan humaniora, memiliki kepekaan dan kesadaran terhadap masalah sosial yang ada dilingkungannya, serta dapat memiliki keterampilan dalam mengkaji dan memecahkan masalah-masalah sosial yang ada tersebut. Oleh sebab itu, guru sekolah dasar dituntut untuk menciptakan suasana yang menyenangkan dalam proses pembelajaran, agar siswa menjadi nyaman dan senang dalam mengikuti pembelajaran yang dilaksanakan oleh guru. Siswa yang merasa nyaman dan senang, maka mereka dapat lebih aktif dalam proses pembelajaran dan mempunyai semangat yang lebih untuk terus belajar.

Berdasarkan hasil observasi pada tanggal 18 Otober 2017 di kelas IV SD Negeri Karangasem IV No. 204 Surakarta, bahwa dalam proses pembelajaran guru masih sering menggunakan pembelajaran yang bersifat konvensional yaitu dengan metode ceramah. Hal ini sejalan dengan hasil wawancara pada tanggal 29 Januari 2018 di SD Negeri Karangasem IV No. 204 Surakarta, yang menunjukkan bahwa kurang tertariknya siswa terhadap mata pelajaran IPS, siswa masih cenderung menghafal dalam mata pelajaran IPS, siswa masih pasif dalam proses pembelajaran, guru masih menggunakan pembelajaran konvensional yang berpusat pada guru atau metode ceramah, sehingga pembelajaran kurang menarik bagi siswa, guru masih belum menggunakan media pembelajaran.

Salah satu materi IPS yang penting untuk dipahami oleh siswa kelas IV adalah materi tentang aktivitas ekonomi. Aktivitas ekonomi merupakan salah satu pokok bahasan IPS yang membutuhkan keaktifan siswa dalam berdiskusi dengan teman sebaya dan saling menyampaikan pendapatnya. Sehingga dalam pembahasan materi aktivitas ekonomi tidak hanya dengan penjelasan guru, tetapi juga dengan kegiatan yang membuat siswa lebih aktif dalam proses pembelajaran yang berlangsung. Materi tentang aktivitas ekonomi memiliki banyak konsep yang harus dapat dipahami oleh siswa kelas IV, hal itu yang masih membuat siswa mendapatkan nilai yang rendah.

Masih rendahnya pemahaman konsep aktivitas ekonomi berkaitan dengan sumber daya alam dapat diperkuat dengan hasil pratindakan yang telah dipeoleh. Hasil pratindakan menunjukkan bahwa hanya 5 atau $16,13 \%$ siswa yang mampu mendapatkan nilai di atas kriteria ketuntasan minimal (KKM) dan sisanya 26 atau $83,87 \%$ siswa masih belum mampu mencapai nilai kriteria ketuntasan minimal (KKM) yang telah ditetapkan sekolah yaitu 70 . Rendahnya hasil pratindakan disebabkan oleh terlalu banyaknya materi dan masih kurangnya media yang digunakan dalam pembelajaran.

Berdasarkan hasil pratindakan yang telah dilakukan, penulis merasa perlu mengadakan perbaikan pada pembelajaran IPS khususnya materi aktivitas ekonomi ber-kaitan dengan sumber daya alam pada siswa kelas IV SD Negeri Karangasem IV No. 204 Surakarta. Peningkatan pemahaman konsep aktivitas ekonomi berkaitan dengan sumber daya alam tersebut tidak serta merta dapat langsung dikuasai oleh siswa. Perlu adanya upaya untuk meningkatkannya seperti strategi, pendekatan, 
metode, media, dan model yang digunakan oleh guru dalam pembelajaran. Sebagai tindak lanjut dalam permasalahan ini, digunakan model pembelajaran sebagai solusi untuk meningkatkan pemahaman konsep aktivitas ekonomi berkaitan dengan sumber daya alam bagi siswa kelas IV. Model pembelajaran yang di-gunakan dalam peningkatan pemahaman konsep aktivitas ekonomi berkaitan dengan sumber daya alam adalah Circuit Learning.

Menurut Huda (2013: 311) model pembelajaran Circuit Learning merupakan strategi pembelajaran yang memaksimalkan pikiran dan perasaan dengan pola penambahan (adding) dan pengulangan (repetition). Menurutnya, strategi ini biasanya dimulai dari tanya jawab tentang topik yang dipelajari, penyajian peta konsep, penjelasan mengenai peta konsep, pembagian ke dalam beberapa kelompok, pengisian lembar kerja siswa disertai dengan peta konsep, penjelasan tentang cara pengisian, pelaksaan presentasi kelompok, dan pembagian reward atau pujian. Model pembelajaran circuit learning memiliki ciri khas dalam penyajian gambar dan peta konsep yang mampu menarik siswa untuk mengikuti pembelajaran IPS secara aktif. Peta konsep digunakan untuk lebih memfokuskan siswa dalam materi yang dipelajari. Model pembelajaran Circuit Learning juga dapat memperbaiki rasa percaya diri siswa dan membuat semua siswa untuk berpartisipasi dalam kelas. Model pembelajaran Circuit Learning menurut Ilie (2013) dalam Science Journal of Education dengan adanya kelompok maka siswa terfasilitasi saat belajar, mereka tidak mendapatkan ilmu hanya dari guru, akan tetapi teman sebaya juga memiliki peran penting.

Kelebihan dari model pembelajaran Circuit Learning menurut Shomin (2016: 35) yaitu kreativitas siswa dalam merangkai kata dengan bahasa sendiri lebih terasah dan konsentrasi yang terbangun membuat siswa fokus dalam belajar. Menurut Kristiarti (2015) model pembelajaran Circit Learning jika diterapkan dengan langkah yang tepat dapat meningkatkan karakter dan hasil belajar siswa.

Penelitian mengenai penggunaan model Circuit Learning pernah dilakukan oleh Liatusyiam, K., Nuryana, \& Nasehudin (2016) dari Universitas IAIN Syekh Nurjati Cirebon yang berjudul "Implementasi Model Pembelajaran Circuit Learning Untuk Meningkatkan Hasil Belajar Siswa Pada Mata Pelajaran IPS Kelas VII Di MTs AI Washliyah" hasilnya terbukti bahwa model pembelajaran circuit learning dapat membuat siswa tertarik pada mata pelajaran IPS. Aktivitas belajar siswa, guru dan hasil belajar juga terbukti dapat ditingkatkan dengan penerapan model pembelajaran circuit learning.

Berdasarkan paparan tersebut, maka perlu untuk mengadakan suatu penelitian dengan judul "Upaya Peningkatkan Pemahaman Konsep Aktivitas Ekonomi Berkaitan Dengan Sumber Daya Alam Melalui Penerapan Model Pembelajaran Circuit Learning (Penelitian Tindakan Kelas Pada Siswa Kelas IV SD Negeri Karangasem IV No. 204 Surakarta Tahun Ajaran 2017/2018)". Penelitian ini bertujuan untuk mengetahui peningkatan pemahaman konsep aktivitas ekonomi berkaitan dengan sumber daya alam melalui penerapan model pembelajaran Circuit Learning pada siswa kelas IV SD Negeri Karangasem IV No. 204 Surakarta tahun ajaran 2017/2018.

\section{METODE}

Penelitian ini berupa Penelitian Tindakan Kelas (PTK) yang dilaksanakan di SD Negeri Karangasem IV No 204 Surakarta tahun ajaran 2017/2018 dengan Kurikulum Tingkat Satuan Pendidikan atau (KTSP). Subjek penelitian yaitu guru kelas IV dan siswa kelas IV SD Negeri Karangasem IV No 204 Surakarta Tahun Ajaran 2017/2018 dengan jumlah siswa 31 yang terdiri dari 15 siswa putra dan 16 siswa putri. Penelitian ini berlangsung pada bulan Januari 2018 sampai Juli 2018.

Sumber data yang digunakan yaitu data primer dan data sekunder. Data primer diperoleh dari guru dan siswa kelas IV SD Negeri Karangasem IV No 204 Surakarta tahun ajaran 2017/2018. Sedangkan data sekunder yaitu berupa silabus, RPP mata 
pelajaran IImu Pengetahuan Sosial (IPS), hasil observasi, dan hasil wawancara terhadap guru dan siswa.

Teknik pengumpulan data berupa wawancara, observasi, tes, dan analisis dokumen. Teknik uji validitas data yang digunakan adalah validitas isi, triangulasi sumber, dan triangulasi teknik. Sedangkan teknik analisis data yang digunakan yaitu data kualitatif menggunakan analisis data interaktif yang terdiri dari empat kegiatan yaitu, pengumpulan data, mereduksi data, penyajian data, dan penarikan kesimpulan.

Penelitian ini dilaksanakan sebanyak dua siklus. Setiap siklus dilaksanakan menjadi dua pertemuan. Kegiatan pokok yang dilakukan dalam penelitian ini yaitu perencanaan, pelaksanaan, pengamatan, dan refleksi yang dilakukan pada setiap siklus.

\section{HASIL DAN PEMBAHASAN}

Berdasarkan hasil wawancara dan observasi pratindakan diperoleh hasil bahwa pemahaman konsep aktivitas ekonomi berkaitan dengan sumber daya alam siswa tergolong masih sangat rendah. Hal tersebut berdasarkan hasil penilaian uji pratindakan dari 31 siswa terdapat 5 siswa atau 16,13\% tuntas dengan nilai mencapai kriteria ketuntasan minimal (KKM) yaitu nilai 70 , sedangkan yang belum tuntas mencapai kriteria ketuntasan minimal (KKM) mencapai 83,87\% atau sebanyak 26 siswa. Hasil uji pratindakan pemahaman konsep aktivitas ekonomi berkaitan dengan sumber daya alam siswa bisa dilihat pada tabel 1 berikut.

Tabel 1, Nilai Pemahaman Konsep Aktivitas Ekonomi Berkaitan Dengan Sumber Daya Alam Siswa Pada Uji Pratindakan

\begin{tabular}{|c|c|c|c|c|c|c|}
\hline \multirow[b]{2}{*}{ No } & \multirow[b]{2}{*}{ Interval } & \multirow{2}{*}{$\begin{array}{c}\text { Nilai } \\
\text { Tengah } \\
\text { (xi) }\end{array}$} & \multirow{2}{*}{$\begin{array}{l}\text { Frekuensi } \\
\text { (fi) }\end{array}$} & \multirow[b]{2}{*}{ fi.xi } & \multicolumn{2}{|c|}{ Persentase (\%) } \\
\hline & & & & & Relatif & Kumulatif \\
\hline 1 & $28-36$ & 32 & 2 & 64 & $6,45 \%$ & $6,45 \%$ \\
\hline 2 & $37-45$ & 41 & 2 & 82 & $6,45 \%$ & $12,9 \%$ \\
\hline 3 & $46-54$ & 50 & 6 & 300 & $19,35 \%$ & $32,25 \%$ \\
\hline 4 & $55-63$ & 59 & 13 & 767 & $41,93 \%$ & $74,18 \%$ \\
\hline 5 & $64-72$ & 68 & 4 & 272 & $12,9 \%$ & $87,08 \%$ \\
\hline 6 & $73-81$ & 77 & 4 & 308 & $12,9 \%$ & $100 \%$ \\
\hline \multirow{2}{*}{\multicolumn{2}{|c|}{$\begin{array}{l}\text { Jumlah } \\
\text { Rata-Rata }\end{array}$}} & 327 & 31 & 1793 & $100 \%$ & \\
\hline & & & & 58,84 & & \\
\hline \multicolumn{2}{|c|}{ Nilai Tertinggi } & & & 80 & & \\
\hline \multicolumn{2}{|c|}{ Nilai Terendah } & & & 28 & & \\
\hline \multirow{2}{*}{\multicolumn{2}{|c|}{$\begin{array}{l}\text { Siswa yang Tuntas } \\
\text { Siswa vana Belum Tuntas }\end{array}$}} & & \multirow{2}{*}{\multicolumn{2}{|c|}{5 siswa $(16,13 \%)$}} & & \\
\hline & & & & 7\%\%) & & \\
\hline
\end{tabular}

Berdasarkan hasil tabel 1 tersebut menunjukkan bahwa sebagian besar siswa belum dapat memahami konsep aktivitas ekonomi berkaitan dengan sumber daya alam. Hal tersebut terlihat bahwa 26 dari 31 siswa masih belum mencapai KKM yang ditetapkan yaitu 70. Analisis hasil pratindakan menunjukkan bahwa rendahnya pemahaman konsep aktivitas ekonomi berkaitan dengan sumber daya alam terletak pada perbedaan intelegensi siswa, materi yang terlalu banyak, dan penggunaan model pembelajaran yang kurang inovatif.

Setelah dilakukan tindakan pada siklus I, nilai pemahaman konsep aktivitas ekonomi berkaitan dengan sumber daya alam mengalami peningkatan melalui penerapan model pembelajaran Circuit Learning pada siklus I dapat dilihat pada tabel 2 sebagai berikut. 
Tabel 2. Nilai Pemahaman Konsep Aktivitas Ekonomi Berkaitan Dengan Sumber Daya Alam Siswa Pada Siklus I

\begin{tabular}{|c|c|c|c|c|c|c|}
\hline \multirow[b]{2}{*}{ No } & \multirow[b]{2}{*}{ Interval } & \multirow{2}{*}{$\begin{array}{c}\text { Nilai } \\
\text { Tengah } \\
\text { (xi) }\end{array}$} & \multirow{2}{*}{$\begin{array}{l}\text { Frekuensi } \\
\text { (fi) }\end{array}$} & \multirow[b]{2}{*}{ fi.xi } & \multicolumn{2}{|c|}{ Persentase (\%) } \\
\hline & & & & & Relatif & Kumulatif \\
\hline 1 & $37-43$ & 40 & 3 & 120 & $9,68 \%$ & $9,68 \%$ \\
\hline 2 & $44-50$ & 47 & 4 & 188 & $12,91 \%$ & $22,59 \%$ \\
\hline 3 & $51-57$ & 54 & 2 & 108 & $6,45 \%$ & $29,04 \%$ \\
\hline 4 & $58-64$ & 61 & 4 & 244 & $12,91 \%$ & $41,95 \%$ \\
\hline 5 & $65-71$ & 68 & 7 & 476 & $22,58 \%$ & $64,53 \%$ \\
\hline 6 & $72-78$ & 75 & 11 & 825 & $35,48 \%$ & $100 \%$ \\
\hline \multicolumn{2}{|c|}{ Jumlah } & 345 & 31 & 1961 & $100 \%$ & \\
\hline \multicolumn{2}{|c|}{ Rata-Rata } & & & 63,26 & & \\
\hline Nila & & & & 77,5 & & \\
\hline \multirow{2}{*}{\multicolumn{2}{|c|}{$\begin{array}{l}\text { Nilai Terendah } \\
\text { Siswa vana Tuntas }\end{array}$}} & & & 37,5 & & \\
\hline & & & \multirow{2}{*}{\multicolumn{2}{|c|}{$\begin{array}{l}13 \text { siswa }(42 \%) \\
18 \text { siswa (58\%) }\end{array}$}} & & \\
\hline \multicolumn{2}{|c|}{$\begin{array}{l}\text { Siswa yang Tuntas } \\
\text { Siswa vana Belum Tuntas }\end{array}$} & & & & & \\
\hline
\end{tabular}

Berdasarkan tabel 2 tersebut terlihat bahwa nilai rata-rata pemahaman konsep aktivitas ekonomi berkaitan dengan sumber daya alam meningkat menjadi 63,26. Peningkatan tersebut juga diikuti persentase ketuntasan $42 \%$ (13 dari 31 siswa). Presentase ketuntasan penelitian pada siklus I tersebut belum mencapai indikator kinerja penelitian yaitu $80 \%$ sehingga penelitian dilanjutkan pada siklus II.

Pada siklus II, nilai pemahaman konsep aktivitas ekonomi berkaitan dengan sumber daya alam melalui model pembelajaran Circuit Learning pada siswa juga mengalami peningkatan. Hal tersebut dapat dilihat pada tabel 3 sebagai berikut.

Tabel 3. Nilai Pemahaman Konsep Aktivitas Ekonomi Berkaitan Dengan Sumber Daya Alam Siswa Siklus II

\begin{tabular}{|c|c|c|c|c|c|c|}
\hline \multirow[b]{2}{*}{ No } & \multirow[b]{2}{*}{ Interval } & \multirow{2}{*}{$\begin{array}{c}\text { Nilai } \\
\text { Tengah } \\
\text { (xi) }\end{array}$} & \multirow{2}{*}{$\begin{array}{l}\text { Frekuensi } \\
\text { (fi) }\end{array}$} & \multirow[b]{2}{*}{ fi.xi } & \multicolumn{2}{|c|}{ Persentase (\%) } \\
\hline & & & & & Relatif & Kumulatif \\
\hline 1 & $60-65$ & 62,5 & 3 & 187,5 & $9,68 \%$ & $9,68 \%$ \\
\hline 2 & $66-71$ & 68,5 & 3 & 205,5 & $9,68 \%$ & $19,36 \%$ \\
\hline 3 & $72-77$ & 74,5 & 0 & 0 & $0 \%$ & $19,36 \%$ \\
\hline 4 & $78-83$ & 80,5 & 6 & 483 & $19,35 \%$ & $38,71 \%$ \\
\hline 5 & $84-89$ & 86,5 & 4 & 346 & $12,91 \%$ & $51,62 \%$ \\
\hline 6 & $90-95$ & 92,5 & 15 & 1387,5 & $48,38 \%$ & $100 \%$ \\
\hline \multirow{2}{*}{\multicolumn{2}{|c|}{$\begin{array}{l}\text { Jumlah } \\
\text { Rata-Rata }\end{array}$}} & 465 & 31 & 2609,5 & $100 \%$ & \\
\hline & & & & 84,18 & & \\
\hline \multicolumn{2}{|c|}{ Nilai Tertinggi } & & & 95 & & \\
\hline \multicolumn{2}{|c|}{ Nilai Terendah } & & & 60 & & \\
\hline \multirow{2}{*}{\multicolumn{2}{|c|}{$\begin{array}{l}\text { Siswa yang Tuntas } \\
\text { Siswa vang Belum Tuntas }\end{array}$}} & & \multirow{2}{*}{\multicolumn{2}{|c|}{26 siswa $(83,87 \%)$}} & & \\
\hline & & & & & & \\
\hline
\end{tabular}

Berdasarkan tabel 3 terlihat bahwa jumlah siswa yang mencapai nilai kriteria ketuntasan minimal (KKM) meningkat menjadi 26 siswa. Meningkatnya pemahaman konsep aktivitas ekonomi berkaitan dengan sumber daya alam juga ditunjukkan dengan meningkatnya nilai rata-rata klasikal yaitu 84,18 . Peningkatan juga ditunjukkan dengan perolehan ketuntasan klasikal yaitu $83,87 \%$. Ketuntasan klasikal yang diperoleh pada siklus II sudah mencapai indikator kinerja penelitian yang telah ditetapkan yaitu $80 \%$ sehingga penelitian dapat dihentikan. 
Perbandingan peningkatan pemahaman konsep aktivitas ekonomi berkaitan dengan sumber daya alam pada uji pratindakan, siklus I, dan siklus II dapat dilihat pada tabel 4 sebagai berikut.

Tabel 4. Data Perbandingan Nilai Pemahaman Konsep Aktivitas Ekonomi
\begin{tabular}{cccc}
\multicolumn{4}{c}{ Berkaitan Dengan Sumber Daya Alam Siswa } \\
\hline & Pratindakan & Siklus I & Siklus II \\
\hline $\begin{array}{c}\text { Nilai Pemahaman } \\
\text { Konsep }\end{array}$ & 58,84 & 63,26 & 84,18 \\
$\begin{array}{c}\text { Persentase } \\
\text { Ketuntasan }\end{array}$ & $16,13 \%$ & $42 \%$ & $83,87 \%$ \\
\hline
\end{tabular}

Berdasarkan tabel 4 tersebut terlihat bahwa nilai pemahaman konsep aktivitas ekonomi berkaitan dengan sumber daya alam siswa mengalami peningkatan pada setiap siklusnya. Peningkatan terjadi pada nilai dan persentase ketuntasan siswa. Hal tersebut menunjukkan bahwa siswa sudah bisa memahami konsep aktivitas ekonomi berkaitan dengan sumber daya alam serta indikator kinerja penelitian telah tercapai.

Berdasarkan hasil analisis pada data penelitian tindakan dari uji pratindakan, tindakan siklus I, dan siklus II dapat disimpulkan bahwa penerapan model pembelajaran circuit learning dapat meningkatkan pemahaman konsep aktivitas ekonomi berkaitan dengan sumber daya alam pada siswa kelas IV SD Negeri Karangasem IV No. 204 Surakarta tahun ajaran 2017/2018. Selain itu, penerapan model pembelajaran Circuit Learning juga dapat meningkatkan kinerja guru dan aktivitas siswa. Meningkatnya kinerja guru dan aktivitas siswa menjadikan kegiatan pembelajaran lebih bermakna.

Pembelajaran aktivitas ekonomi berkaitan dengan sumber daya alam pada siswa kelas IV SD Negeri Karangasem IV No. 204 Surakarta dilakukan dengan penerapan model pembelajaran circuit learning dikarenakan model pembelajaran tersebut memakai media pembelajaran gambar dan peta konsep yang mampu menarik siswa untuk mengikuti pembelajaran. Hal tersebut sesuai dengan pendapat Huda (2015: 311) bahwa model pembelajaran Circuit Learning dapat melatih kreativitas dan konsentrasi siswa untuk fokus pada peta konsep yang telah disajikan.

Pembelajaran IPS materi aktivitas ekonomi berkaitan dengan sumber daya alam dilaksanakan sesuai dengan langkah-langkah model pembelajaran circuit learning. Langkah model pembelajaran circuit learning yang diterapkan dalam pembelajaran IPS materi aktivitas ekonomi berkaitan dengan sumber daya alam pada siswa kelas IV SD Negeri Karangasem IV No. 204 Surakarta terdiri dari 8 langkah yaitu: (1) pengkondisian siswa; (2) melakukan apersepsi; (3) menempelkan dan tanya jawab gambar; (4) menempelkan dan tanya jawab peta konsep; (5) berdiskusi secara kelompok; (6) siswa membuat peta konsep; (7) mempresentasikan hasil diskusi; (8) refleksi. Pada siklus I media yang digunakan berupa gambar-gambar, sedangkan siklus II menggunakan video pembelajaran.

Berdasarkan data dan pembahasan di atas, maka dapat dipaparkan bahwa (1) penerapan model pembelajaran Circuit Learning dalam pembelajaran aktivitas ekonomi berkaitan dengan sumber daya alam pada siswa kelas IV SD Negeri Karangasem IV No. 204 Surakarta dapat mendorong siswa lebih aktif dalam proses pembelajaran, dan (2) penerapan model pembelajaran circuit learning dapat meningkatkan pemahaman konsep aktivitas ekonomi berkaitan dengan sumber daya alam pada siswa kelas IV SD Negeri Karangasem IV No. 204 Surakarta tahun ajaran 2017/2018. 


\section{SIMPULAN}

Berdasarkan hasil analisis data dan pembahasan maka disimpulkan bahwa penerapan model pembelajaran circuit learning dapat meningkatkan pemahaman konsep aktivitas ekonomi berkaitan dengan sumber daya alam pada siswa kelas IV SD Negeri Karangasem IV No. 204 Surakarta tahun ajaran 2017/2018.

Berkaitan dengan hasil penelitian, peneliti mengajukan saran 1) bagi guru, hendaknya dalam pembelajaran dengan menggunakan model pembelajaran circuit learning terlebih dahulu mengkondisikan siswa, menarik perhatian siswa, dan memberi motivasi kepada siswa; 2) bagi sekolah, sebaiknya lebih menghimbau kepada para guru untuk menambah ilmu pengetahuan tentang model pembelajaran yang kreatif dan inovatif sehingga dapat meningkatkan hasil belajar siswa; 3) bagi peneliti lain yang ingin melakukan penelitian terkait hendaknya menguasai kompetensi dasar secara matang dan mempersiapkan penelitian secara maksimal.

\section{DAFTAR PUSTAKA}

Heruman. (2012). Model Pembelajaran Matematika di Sekolah Dasar.Bandung: Remaja Rosdakarya.

Huda, Miftahul. (2015). Model-Model Pengajaran dan Pembelajaran Isu-Isu Metodis dan Paradigmatis. Yogyakarta: Pustaka Pelajar.

Ilie, Vali. (2013). C.I.R.C.U.I.T. Model- a Strategic Option in the Pedagogical Training of the Constructivist Teacher. Romania: Science Journal of Education, 1 (5), 6876.

Kristiarti, A., Suripto., \& Suryandari, C. K. (2015). Penerapan Model Circuit Learning dalam Peningkatan Karakter dan Hasil Belajar PKn tentang Kebebasan Berorganisasi pada Siswa Kelas V SD Negeri 2 Prembun Tahun Ajaran 2014/2015. Kalam Cendekia, Vol 3, No 5.1, 462-467.

Liatusyiam, K., Nuryana, \& Nasehudin. (2016). Implementasi Model Pembelajaran Circuit Learning untuk Meningkatkan Hasil Belajar Siswa pada Mata Pelajaran IPS Kelas VII di MTs Al-Washliyah Talun Kabupaten Cirebon. Cirebon: Jurnal Edueksos, Volume V, No 2.

Shoimin, Aris. (2016). 68 Model Pembelajaran Inovatif dalam Kurikulum 2013. Yogyakarta: Ar-Ruzz Media.

Susanto, Ahmad. (2016). Teori Belajar Pembelajaran di Sekolah Dasar. Jakarta: Prenadamedia Group. 